Buxton, E. W., Last, F. T. \& Nour, M. A. (1957). J. gen. Microbiol. 16, 764-773

\title{
Some Effects of Ultraviolet Radiation on the Pathogenicity of Botrytis fabae, Uromyces fabae and Erysiphe graminis
}

\author{
By E. W. BUXTON, F. T. LAST AND M. A. NOUR* \\ Rothamsted Experimental Station, Harpenden, Hertfordshire
}

SUMMARY: Ultraviolet irradiation of spores of three leaf-infecting fungi, Botrytis fabae, Uromyces fabae (causes of 'chocolate spot' and rust of broad beans, respectively) and Erysiphe graminis (cause of barley powdery mildew), decreased their pathogenicity, as assessed by counts of local lesions or pustules. The infectivity of $B$. fabae was lost more rapidly than the ability to form colonies on agar; with $\boldsymbol{E}$. graminis infectivity was lost more rapidly than the ability to germinate. Ultraviolet radiation damage to spores of all three fungi was mitigated by exposure to daylight after irradiation. The extent of such photoreactivation of $B$. fabae was the same whether the spores were on the host plant or in vitro. Ultraviolet irradiation of leaves before inoculation decreased the number of pustules of $\boldsymbol{E}$. graminis on barley, had no effect on the pustule number caused by $U$. fabae and increased the number of lesions caused by $B$. fabae on broad beans. Rubbing leaves with Celite before inoculation also increased the number of $\boldsymbol{B}$. fabae lesions. Retaining u.v.irradiated broad bean plants in daylight or darkness after inoculation with unirradiated spores of $\boldsymbol{B}$. fabae did not significantly alter the lesion number. In contrast, more pustules of $\boldsymbol{E}$. graminis developed on u.v.-irradiated barley leaves kept in daylight than in darkness.

Ultraviolet (u.v.) radiation can affect micro-organisms in many ways, and some of the consequences can be mitigated by exposure to visible light afterwards. Kelner (1949) found that u.v.-irradiated bacteria and spores of fungi that would not grow when left in darkness, grew when illuminated. A comparable phenomenon, which has come to be called 'photoreactivation', has also been reported with bacteriophages (Dulbecco, 1950) and plant viruses (Bawden \& Kleczkowski, 1955), but with these it occurs only when infected hosts are illuminated and not when the u.v.-irradiated viruses are illuminated in vitro. Exposure of leaves to u.v. radiation also affects their susceptibility to infection by plant viruses; for example, immediately after French bean leaves are irradiated, they resist infection with tobacco necrosis viruses, but when left in the light the leaves recover their initial susceptibility (Bawden \& Kleczkowski, 1952) or may even become more susceptible than unirradiated leaves (Benda, 1955).

The loss of infectivity by spores of Botrytis fabae Sardiña caused by u.v. radiation can also be counteracted by exposing the spores to visible light (Last \& Buxton, 1955). The work we describe now was done to compare the effects of u.v. radiation on the host and parasite relations of viruses with those for both obligately and facultatively parasitic fungi.

* On study leave from University of Khartoum, Sudan. 


\section{METHODS}

Broad bean with Botrytis fabae and Uromyces fabae (Pers.) de Bary Broad beans cv. Seville Longpod were grown in 8 in. pots containing John Innes potting compost and were used for experiments when 12-18 days old. Ultraviolet radiation, more than $95 \%$ of which was wavelength $2537 \AA$., was provided by a Hanovia XII medium-pressure lamp (lamp A). Bean leaves were irradiated at $20 \mathrm{~cm}$. from the tube of the lamp, and spores of the two fungi $(0 \cdot 2 \mathrm{ml}$. of dense suspensions in glass cavity slides of depth $1 \mathrm{~mm}$.) at $40 \mathrm{~cm}$. At these distances the radiation intensities were $c .692$ and $173 \mu \mathrm{W} . / \mathrm{cm} .^{2}$ respectively. Spores of Botrytis fabae were used only from cultures 10-20 days old and the concentrations used in the water suspensions were increased for the older cultures to allow for their decreased infectivity (Last \& Hamley, 1956). The spores were prepared from colonies grown at $20^{\circ}$ on an agar medium constituted as follows (g./l. water): $\mathrm{KH}_{\mathbf{2}} \mathrm{PO}_{\mathbf{4}}, \mathbf{5 \cdot 0} ; \mathrm{MgSO}_{4} . \mathbf{7} \mathbf{H}_{\mathbf{2}} \mathrm{O}, \mathbf{1} \cdot \mathbf{0}$; $\mathrm{FeCl}_{3} 6 \mathrm{H}_{2} \mathrm{O}, 0.2 ; \mathrm{KNO}_{3}, 2 \cdot 0 ; \mathrm{CaCl}_{2}, 0.01$; glucose, 20.0; peptone (Bacteriological, Hopkin \& Williams Ltd.), 5•0; agar, (Hopkin \& Williams Ltd.) 30・0.

Stock cultures of Uromyces fabae were retained by infecting beans with water suspensions of uredospores.

Inoculations to leaves were made by the method described by Last \& Hamley (1956), and each bifoliate leaf was split for treatment into four halfleaflets, enabling a $4 \times 4$ Latin square experimental design to be done on plants with four leaves. When Botrytis fabae was used, the leaves, attached to part of the stem, were detached from the plant, stood in water and placed in a saturated atmosphere under a glass bell-jar. Lesions were counted after incubation for $48 \mathrm{hr}$. at $c .20^{\circ}$ and their numbers ( $x$ lesions/half-leaflet) were transformed to $z$, where

$$
z=\log _{10} \frac{1}{2}\left[x+c+\sqrt{ }\left(x^{2}+2 c x\right)\right] \text { and } c=20 \text { (Kleczkowski, 1955). }
$$

Leaves inoculated with Uromyces fabae were not detached; plants were kept in a saturated atmosphere under bell-jars for 4 days, then moved into the glasshouse. Colony counts were made after 10 days.

Barley with Erysiphe graminis $D C$. For germination and infectivity tests with $E$. graminis DC, either dry microscope slides or the upper surfaces of detached leaves were coated with conidia shaken from infected leaves held above them, and were then incubated at room temperature, c. $15^{\circ}$. The detached barley leaves cv. Plumage Archer, each attached to $1.5 \mathrm{~cm}$. of its sheath, were stood singly in test tubes filled with tap water to a depth of $1 \mathrm{~cm}$.; the slides were put in a saturated atmosphere in Petri dishes.

For u.v.-irradiating Erysiphe graminis, a different lamp was used; it was a Hanovia medium-pressure lamp giving u.v. radiation of which more than $95 \%$ was of wavelength $2537 \AA$. and an intensity of $108 \mu \mathrm{W} . / \mathrm{cm} .^{2}$ when $20 \mathrm{~cm}$. above the leaves and slides (lamp B). Only half of the leaf or coated slide was irradiated and the unexposed half acted as a control. When testing for inactivation by $u . v$. radiation, the leaves inoculated with spores were kept in 
darkness for 2 days and then exposed to daylight until pustules were counted; the slides were kept in darkness until germination counts were made. The zones within $1 \mathrm{~cm}$. of the boundary were ignored.

The percentage germination after 2 days on the u.v.-irradiated section of the slide was corrected to allow for the incomplete germination of the unirradiated spores. The effect on infectivity was measured after 5 days by expressing the number of colonies/unit area of exposed section of leaf as a percentage of the number on its complementary unexposed section. All treatments were replicated at least five times.

\section{RESULTS}

\section{Survival curves after ultraviolet irradiation}

Agar plates, each spread with 1000 spores of Botrytis fabae, and cavity slides containing spore suspensions of either $B$. fabae or Uromyces fabae were irradiated for different periods of time. Subsequently, the agar plates were

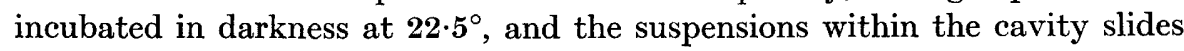
were inoculated to broad bean leaves which were then also kept in darkness. Because the numbers of lesions on bean leaves are not simply related to the inoculum concentration, a dilution series of unirradiated spores of B. fabae was made at the same time. From it the percentage survivals, which were plotted on a logarithmic scale (Fig. 1 A), were derived.

The decrease in viability (ability to form colonies on agar) and of infectivity (ability to form lesions on the host plant) did not follow the course of a firstorder reaction, i.e. the logarithms of proportions of spores viable and infective plotted against the times of irradiation did not give straight lines. The lines were at first almost horizontal and then turned downwards to approach asymptotically straight lines, resembling the course of so-called 'multiple hit' curves. Logarithmic estimates of 'multiplicity', obtained by extrapolating the descending straight parts of the curves to the ordinate, show that these spores behave as if $c .8$ centres had to be affected to make them non-viable, and only three to four centres to make them non-infective.

An exposure of 1 min. to u.v. radiation made a greater proportion of Botrytis fabae spores non-infective than of Uromyces fabae spores (Fig. 1B). These data are the actual numbers of lesions or pustules/half-leaflet, and have not been corrected for percentage survival. In contrast to $B$. fabae the decline in germination and infectivity of conidia of Erysiphe graminis with increasing exposure to u.v. radiation seems to follow the course of a first-order reaction at least with exposures up to $1 \mathrm{~min}$. Like $B$. fabae, however, the viability of $\boldsymbol{E}$. graminis in vitro was less affected by u.v. radiation than was its infectivity. Although the effects of u.v. radiation on the infectivity of $\boldsymbol{E}$. graminis were measured on conidia already inoculated to barley leaves, results described later show that the decline in pustule number caused by exposure of up to 1 min. cannot be attributed to changes in the host's susceptibility.

Although the conidia of Botrytis fabae were in suspension, and those of Erysiphe graminis were not, the exposures necessary to decrease germination 
by $50 \%$ probably reflect the different sensitivities of the two fungi, 20 and 127 sec. for $E$. graminis and $B$. fabae, respectively (Fig. 1C).

Survival curves, on agar only, were also obtained for Aspergillus niger, Fusarium oxysporum f. pisi races 1 and 2 and Fusarium solani f. pisi. Of these, the survival curves of $F$. oxysporum f. pisi races 1 and 2 , which consisted

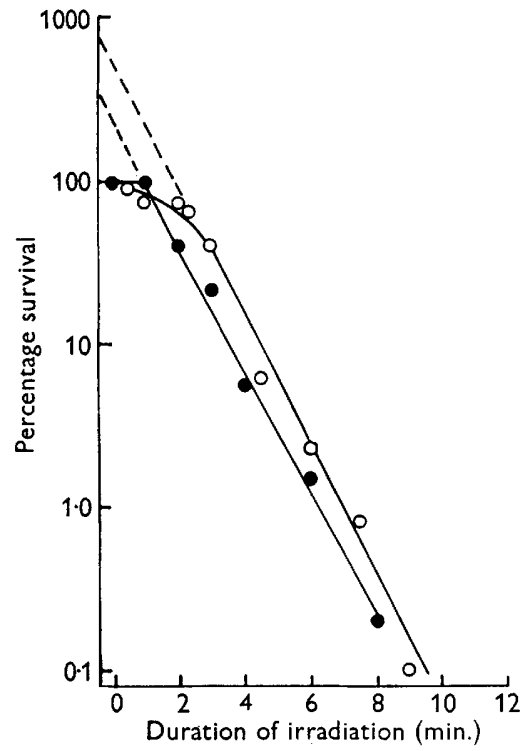

A

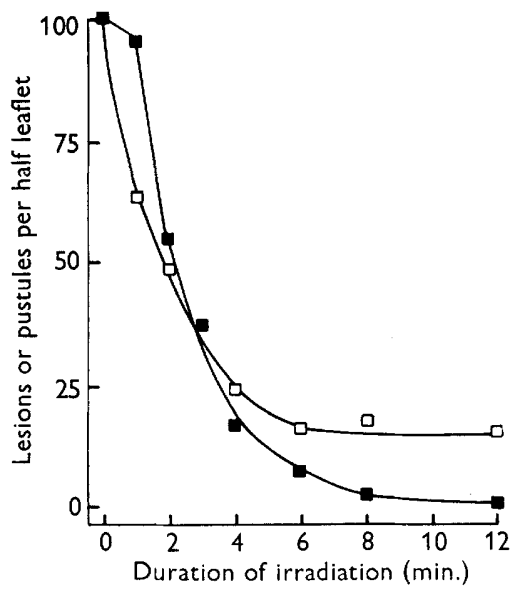

B

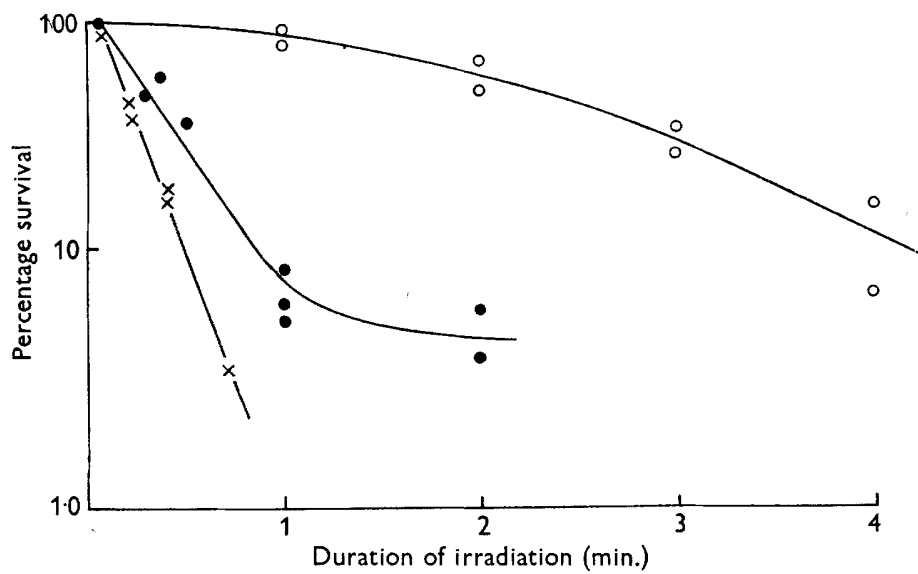

C

Fig. 1. Ultraviolet radiation survival curves of Botrytis fabae and Uromyces fabae. (A) Relation between time of exposure to lamp $A$ and \% survival of $B$. fabae. $\bullet=$ survivors forming lesions on bean leaves; $O=$ survivors forming colonies on agar media. (B) Relation between time of exposure to lamp $A$ and number of lesions or pustules formed/halfleaflet by $B$. fabae and $U$. fabae. $\square=B$. fabae; $\square=U$. fabae. (C) The effect of ultraviolet radiation with lamp B on the germination of conidia of Erysiphe graminis (-) and $B$. fabae $(\mathrm{O})$, and on the infectivity of $\boldsymbol{E}$. graminis $(\times)$. 
mainly of uninucleate microconidia, followed the course of a first-order reaction, whereas those of $A$. niger and $F$. solani were similar to those obtained for Botrytis fabae.

When Botrytis fabae spores were u.v.-irradiated at different times after inoculation to leaves, the survival curves varied with the delay (Fig. 2). After each period of post-inoculation delay, leaves were u.v.-irradiated for $0,2,4$ and $8 \mathrm{~min}$. When the irradiation was immediately after inoculation, the

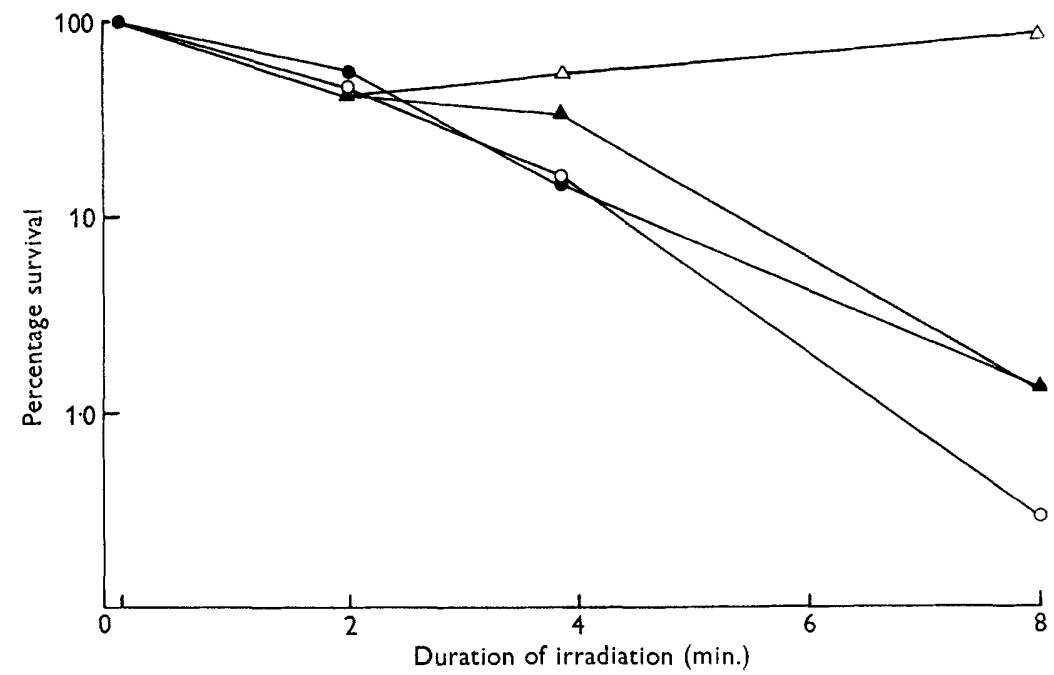

Fig. 2. Effect of u.v.-irradiating broad bean leaves for various times, at different intervals after inoculation with Botrytis fabae, on the numbers of lesions formed. Time after inoculation when irradiated $\bigcirc-0,0$ hr.; - -2 hr.; $\Delta-\Delta, 4$ hr.; $\Delta-\Delta, 7 \mathrm{hr}$.

number of lesions, expressed as a percentage of those formed without any irradiation, decreased as the time of irradiation increased. Irradiation $7 \mathrm{hr}$. after inoculation had no effect, presumably because spores had by then germinated and the fungus had penetrated the host, where it was shielded from the u.v. radiation. With Erysiphe graminis, exposure to u.v. radiation was less damaging when done $70 \mathrm{hr}$. after inoculation than after $20 \mathrm{hr}$. (Table 3). Comparable effects were obtained by Bawden \& Harrison (1955) when French bean leaves were u.v.-irradiated at different intervals after they had been inoculated with a tobacco necrosis virus.

\section{Photoreactivation}

Exposure of spores of Botrytis fabae u.v.-irradiated for $3.5 \mathrm{~min}$. (10\% survival in Fig. 1 A) to daylight before inoculation to plants, which were then kept in darkness, increases the infectivity of the spores as measured by lesion counts (Last \& Buxton, 1955). Table 1 shows that photoreactivation occurred to the same extent whether the spores were exposed to daylight on inoculated leaves (A) or in cavity slides before they were inoculated to leaves (B).

The effects of u.v. radiation on spores of Uromyces fabae (Table 2) and Erysiphe graminis (Table 3) were also mitigated by exposure to daylight. When 
irradiated suspensions, kept in cavity slides in darkness or light for $7 \mathrm{hr}$. were inoculated to plants subsequently kept in darkness for 4 days, 5 and 17 pustules of $U$. fabae/half-leaflet developed in one experiment and 5 and 10 in another. When the inoculated plants were kept in daylight, u.v.-irradiated spores kept in the light for $7 \mathrm{hr}$. before they were used as inoculum produced no more infections than spores kept in darkness. This implies that photoreactivation occurred on the plants and that $7 \mathrm{hr}$. delay before exposure to light did not diminish the extent of photoreactivation.

Table 1. The effect of exposing u.v.-irradiated spores of Botrytis fabae to daylight on the host plant and in vitro

\begin{tabular}{|c|c|c|}
\hline \multicolumn{3}{|c|}{$\begin{array}{l}\text { No. of lesions/half-leaflet. } \\
\text { Treatment of spores for } \\
7 \mathrm{hr} \text {. after irradiation }\end{array}$} \\
\hline $\begin{array}{l}\text { Light, } \\
\qquad L\end{array}$ & $\begin{array}{c}\text { Dark, } \\
D\end{array}$ & $\begin{array}{c}\text { Effect of light } \\
(L-D)\end{array}$ \\
\hline$(2 \cdot 16)$ & $(1 \cdot 75)$ & $(0 \cdot 41)$ \\
\hline 125 & 38 & \\
\hline$(2 \cdot 37)$ & $(2 \cdot 01)$ & $(0 \cdot 36)$ \\
\hline 214 & 83 & \\
\hline
\end{tabular}

A. Suspension inoculated to beans immediately after irradiation

B. Suspension left in slides for $7 \mathrm{hr}$. after irradiation before being inoculated to leaves

Figures in parentheses: transformed data. Significant difference between means of transformed data for $P=0.05$ is 0.17 .

Table 2. Effects of exposing u.v.-irradiated Uromyces fabae spores to daylight for $7 \mathrm{hr}$. before inoculation to beans, and of subsequently keeping the inoculated plants in light or darkness

Pre-inoculation treatment
Spores in daylight
Spores in darkness
Spores in daylight
Spores in darkness

$\overbrace{\text { Exp. } 1}^{\text {No. of pustules/half-leaflet }}$

Plants in daylight after inoculation

2413

$20 \quad 13$

Plants in darkness after inoculation

Spores in daylight
Spores in darkness

$\begin{array}{rr}17 & 10 \\ 5 & 5\end{array}$

Last \& Buxton (1955) found that exposure of Botrytis fabae spores for $2 \mathrm{hr}$. in cavity slides to daylight immediately after u.v. irradiation at least doubled the number of lesions formed when they were inoculated to bean leaves. When, however, irradiated spores were photoreactivated immediately after inoculation to leaves, $\mathbf{5 \cdot 5} \mathrm{hr}$. was needed to produce a significant increase in lesion number, and a further $5 \mathrm{hr}$. produced no further increase.

The relative effect of photoreactivation increased as the exposure of Botrytis fabae and Erysiphe graminis spores to u.v. radiation increased. After 3 min. u.v. irradiation the ratio of the number of lesions formed by $\boldsymbol{B}$. fabae spores in cavity slides in light to those kept in darkness for $7 \mathrm{hr}$. before inoculation to plants (which were then placed in darkness) was 2.6; after 7 min. 
Table 3. The effect of exposing u.v.-irradiated conidia of Erysiphe graminis to daylight on (a) germination and $(b)$ infectivity

(a) Effect on germination

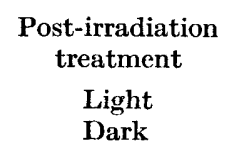

Time after inoculation when irradiated (hr.)

20

70
Post-irradiation treatment

Light

Dark

Light

Dark
Period of exposure to u.v. radiation

\begin{tabular}{|c|c|c|}
\hline 5 sec. & $\begin{array}{l}20 \text { sec. } \\
\text { Germination }(\%)\end{array}$ & 60 sec. \\
\hline 100 & 98 & 100 \\
\hline 98 & $60 \cdot 2$ & $8 \cdot 3$ \\
\hline
\end{tabular}

(b) Effect on infectivity

Duration of exposure to u.v. radiation

$\overbrace{10 \mathrm{sec} .}^{20 \mathrm{sec} .} 60 \mathrm{sec}$.

No. pustules from irradiated conidia as \% from unirradiated (transformed to angles for analysis)

$\begin{array}{rrr}73 \cdot 1 & 82 \cdot 2 & 78 \cdot 6 \\ 29 \cdot 9 & 21 \cdot 8 & 0 \cdot 0 \\ 65 \cdot 0 & 74 \cdot 1 & 75 \cdot 4 \\ 69 \cdot 7 & 48 \cdot 8 & 26 \cdot 3\end{array}$

Significant difference between means of transformed data for $P=0.05$ is $21 \cdot 6$ (original data)

$\begin{array}{llllr}20 & \text { Light } & 85 \cdot 9 & 95 \cdot 3^{*} & 90 \cdot 8^{*} \\ \text { Dark } & 30 \cdot 2 & 17 \cdot 2 & 0 \cdot 0 \\ \text { Light } & 81 \cdot 8 & 83 \cdot 6 & 89 \cdot 1 \\ \text { Dark } & 81 \cdot 2 & 56 \cdot 4 & \mathbf{2 4 . 5}\end{array}$

* Figures referred to in text.

Table 4. The effect of light and dark post-irradiation treatments on the numbers of lesions formed/half-leaflet by spore suspensions of Botrytis fabae exposed to $u . v$. radiation

Duration of exposure to u.v. radiation (min.)

\begin{tabular}{|c|c|c|c|c|c|c|c|c|c|}
\hline \multirow{2}{*}{$\begin{array}{c}\text { Post- } \\
\text { irradiation } \\
\text { treatment }\end{array}$} & $\mathbf{3}$ & 4 & 4.5 & 5 & $5 \cdot 5$ & 6 & $6 \cdot 5$ & 7 & Mean \\
\hline & \multicolumn{9}{|c|}{ Lesions/half-leaflet (transformed data) } \\
\hline Light & $1 \cdot 74$ & $1 \cdot 76$ & $1 \cdot 88$ & $1 \cdot 74$ & $1 \cdot 63$ & $1 \cdot 67$ & $1 \cdot 51$ & 1.55 & $1 \cdot 69 *$ \\
\hline Dark & $1 \cdot 49$ & $1 \cdot 32$ & $1 \cdot 24$ & $1 \cdot 20$ & $1 \cdot 17$ & $1 \cdot 11$ & $1 \cdot 12$ & $1 \cdot 12$ & $1 \cdot 22$ \\
\hline Mean $\dagger$ & $1 \cdot 61$ & 1.54 & 1.56 & $1 \cdot 47$ & $1 \cdot 40$ & $1 \cdot 39$ & 1.32 & $1 \cdot 34$ & - \\
\hline
\end{tabular}

* Significant difference between means for $P=0.05$ is 0.05 .

$\uparrow$ Significant difference between means for $P=0.05$ is 0.09 .

\begin{tabular}{|c|c|c|c|c|c|c|c|c|c|}
\hline \multirow[b]{2}{*}{ Light } & \multicolumn{9}{|c|}{ Detransformed means } \\
\hline & 37 & 39 & 57 & 37 & 25 & 29 & $15 \cdot 5$ & 18 & - \\
\hline \multirow[t]{3}{*}{ Dark } & 14 & $5 \cdot 5$ & 3 & 2 & 2 & 1 & 1 & 1 & - \\
\hline & \multicolumn{9}{|c|}{ Ratio of light/dark } \\
\hline & $2 \cdot 6$ & $7 \cdot 1$ & $19 \cdot 0$ & 18 . & 12 . & 29. & $15 \cdot 5$ & $18 \cdot 0$ & - \\
\hline
\end{tabular}


u.v. irradiation the ratio was 18 (Table 4). With $E$. graminis, photoreactivation of spores $u . v$.-irradiated for $20 \mathrm{sec}$. increased pustule number from 17 to $95 \%$ of pustules formed by unirradiated spores and, after u.v. irradiation for $60 \mathrm{sec}$., photoreactivation increased pustules from 0 to $90 \%$ (Table 3 ).

The relatively greater effects of photoreactivation with increasing degree of u.v. irradiation has been found with all biological systems tested and has been called 'the dose reduction principle' (Kelner, 1949). The effects of u.v. irradiation on the fungi used in our experiments differ from the results obtained in similar work on bacterial and plant viruses. Viruses can be photoreactivated only after they have infected host cells (Dulbecco, 1950; Bawden \& Kleczkowski, 1953), whereas fungi, whether obligate or facultative parasites, can be photoreactivated in vitro. The capacity to do this may lie in cell components of fungus spores which are lacking in the non-cellular viruses.

\section{Effects of ultraviolet radiation on leaf susceptibility}

Bawden \& Kleczkowski (1952) showed that u.v. irradiation of French bean leaves before inoculation increased their resistance to infection by tobacco necrosis virus, and that susceptibility was regained by their subsequent exposure to daylight. Similarly, u.v. irradiation increased the resistance of barley leaves to infection with Erysiphe graminis, and again, this resistance was lowered by their subsequent exposure to daylight. A minimum of $4 \mathrm{~min}$. u.v. irradiation was necessary to detect this effect (Table 5). In contrast, u.v. irradiation of broad bean leaves for $4 \mathrm{~min}$. before inoculation increased both the number and the size of lesions formed by Botrytis fabae (Table 6); it did not affect the lesions produced by Uromyces fabae.

Table 5. Effects of irradiating barley leaves before inoculation with Erysiphe graminis, and of subsequent exposures to daylight and darkness on numbers of pustules developing

\begin{tabular}{|c|c|c|c|c|}
\hline \multicolumn{5}{|c|}{ uration of exposure to u.v. radiation (mi } \\
\hline 1 & 2 & 4 & 6 & 8 \\
\hline \multicolumn{5}{|c|}{$\begin{array}{l}\text { Numbers of pustules/unit area on irradiated section as } \\
\% \text { of pustule number on unirradiated section }\end{array}$} \\
\hline 100 & 100 & $42 \cdot r$ & 11 & 0.0 \\
\hline 100 & 89 & $0 \cdot($ & $2 \cdot 6$ & 0.0 \\
\hline
\end{tabular}

Table 6. Effects on bean leaves of $(a)$ rubbing with Celite and $(b)$ u.v. radiation before inoculation with Botrytis fabae

(a) Number of lesions/half-leaflet

With Celite Without Celite

$184 \quad 82$

(b) Ratio of lesions on irradiated to unirradiated half-leaflets

Duration of exposure to u.v. radiation (min.)

Ratio

$\begin{array}{cccc}1 & 2 & 4 & 8 \\ 1.2 & 2.2 & 2.6 & 3.4\end{array}$


Increasing the u.v. irradiation of the leaves from 1 to $8 \mathrm{~min}$. progressively increased the susceptibility of bean leaves to Botrytis fabae. With Uromyces fabae, which needed 10 days to cause lesions to appear, compared with 1 day with $B$. fabae, similar observations were not possible because leaves irradiated for $4 \mathrm{~min}$. bronzed and died. Placing u.v.-irradiated plants in light or darkness after inoculation with $\boldsymbol{B}$. fabae did not significantly alter their susceptibility.

The effect of irradiating leaves before inoculation on the number of lesions given by Botrytis fabae was similar to that caused by rubbing the leaves with a Celite paste immediately before inoculation (Table 6). Both u.v. radiation and rubbing with Celite may act by altering the leaf cells so that substances which promote infection by $B$. fabae are exuded in greater amount. Stimulation of infection by foliar exudates was demonstrated by Brown (1922) with B. cinerea, and Norell (1954) showed that irradiation of potato disks with u.v. radiation increased the exudation of substances which stimulated the growth of Fusarium culmorum. In attempting to explain this, Norell considered that a vital substance in the cell became oxidized by oxidizing agents formed as a result of the u.v. irradiation, or possibly by a direct photooxidative process. If such a substance, in its reduced state, maintained cell permeability, the u.v. irradiation might cause increased permeability, thus leading to increased exudation from the cells. If this occurred with irradiated bean leaves, once sufficient cell exudate was present on the leaf surface to stimulate infection by $B$. fabae spores, it seems unlikely that subsequent exposure of the leaves to daylight would have any effect on their susceptibility. The obligate parasites Uromyces fabae and Erysiphe graminis are less likely than $B$. fabae to respond to leaf exudates and infection by these organisms probably depends on the internal metabolism of the leaf cells. Like plant viruses, successful infection by them may depend on the nucleoprotein metabolism of the host cell, and if this were impaired by u.v. irradiation, the leaves would become resistant.

\section{REFERENCES}

Bawden, F. C. \& Harrison, B. D. (1955). Studies on the multiplication of a tobacco necrosis virus in inoculated leaves of French-bean plants. J. gen. Microbiol. 13, 494.

Bawden, F. C. \& Kleczkowski, A. (1952). Ultraviolet injury to higher plants counteracted by visible light. Nature, Lond. 169, 90.

Bawden, F. C. \& KLeczkowskr, A. (1953). The behaviour of some plant viruses after exposure to ultraviolet radiation. J. gen. Microbiol. 8, 145.

Bawden, F. C. \& Kleczkowski, A. (1955). Studies on the ability of light to counteract the inactivating action of ultraviolet radiation on plant viruses. $J$. gen. Microbiol. 13, 370.

Benda, G. T. A. (1955). Some effects of ultraviolet radiation on leaves of French bean (Phaseolus vulgaris L.). Ann. appl. Biol. 43, 71.

Brown, W. (1922). Studies in the physiology of parasitism. VIII. On the exosmosis of nutrient substances from the host tissue into the infection drop. Ann. Bot., Lond. 36, 101.

Dulbecco, R. (1950). Experiments on photoreactivation of bacteriophages inactivated by ultraviolet radiation. J. Bact. 59, 329. 
Kelnkr, A. (1949). Photoreactivation of ultraviolet-irradiated Escherichia coli, with special reference to the dose-reduction principle and to ultraviolet-induced mutation. J. Bact. 58, 511.

Kueczkowski, A. (1955). The statistical analysis of plant virus assays: a transformation to include lesion numbers with small means. J. gen. Microbiol. 13, 91.

Last, F. T. \& Buxton, E. W. (1955). Photoreactivation of Botrytis fabae Sardiña measured by a local-lesion technique. Nature, Lond. 176, 655.

Last, F. T. \& Hamlex, R. E. (1956). A local-lesion technique for measuring the infectivity of conidia of Botrytis fabae Sardiña. Ann. appl. Biol. 44, 410.

Norell, I. (1954). 'The effect of ultraviolet light on the resistance of potato tubers to Fusarium species. Physiol. Plant. 7, 797.

(Received 15 January 1957) 